\title{
Impact of tropical volcanic eruptions on Hadley circulation using a high-resolution AGCM
}

\author{
Muhammad Mubashar Dogar ${ }^{1,2, *}$ \\ ${ }^{1}$ Earth Science and Engineering, King Abdullah University of Science and Technology, Thuwal 23955-6900, Saudi Arabia \\ ${ }^{2}$ Global Change Impact Studies Centre (GCISC), Ministry of Climate Change, Islamabad, Pakistan
}

The direct radiative effects of volcanic eruptions resulting in solar dimming, stratospheric warming, global surface cooling and reduction in rainfall are well documented. However, eruptions also cause indirect climatic impacts that are not well understood. For example, solar dimming induced by volcanic aerosols could cause changes in tropical Hadley circulation that in turn largely affect evaporation and precipitation patterns. Therefore, understanding the sensitivity of $\mathrm{HC}$ to volcanism is essential, as this circulation is directly related to precipitation changes in the tropics and with other large-scale circulations. Hence, to better understand the post-eruption sensitivity of $\mathrm{HC}$ and associated changes in the hydrologic cycle, simulations for the El Chichón and Pinatubo tropical eruptions were conducted using a high-resolution atmospheric model (HIRAM), effectively at 25 and $50 \mathrm{~km}$ grid spacing. The model simulated results are then compared with observational and reanalysis products. Both the model and observational analysis show posteruption weakening, shrinking and equatorward displacement of the updraft branch of $\mathrm{HC}$ caused by the equatorward shift of midlatitude jets and hemispheric land-sea thermal gradient. The Intertropical Convergence Zone (ITCZ) is tightly coupled to the rising branch of $\mathrm{HC}$, hence, post-eruption weakening and equatorward displacement of $\mathrm{HC}$ cause weakening of ITCZ that adversely affects rainfall distribution in the monsoon-fed regions, especially the South Asian and African tropical rain-belt regions. The modelproduced post-eruption distribution of cloud contents suggests a southward shift of ITCZ. The HIRAM results are largely in agreement with the reanalysis, observations and previous studies indicating that this model performs reasonably well in reproducing the global and regional-scale dynamic changes caused by volcanic radiative forcing.

Keywords: Atmospheric models, jet streams, monsoon circulation and ITCZ, tropical volcanic eruptions.

THE Hadley circulation, a global-scale meridional overturning circulation in the tropical atmosphere, plays a

\footnotetext{
*e-mail: muhammad.dogar@kaust.edu.sa
}

significant role in the inter-hemispheric distribution of heat and water vapours ${ }^{1-7}$. The Hadley circulation is responsible for trade winds in the tropics and controls low-latitude weather patterns. An intensification/weakening of the Northern Hemisphere (NH) Hadley Cell (HC) circulation in boreal summer leads to an increased/decreased water vapour inflow across the equator into the $\mathrm{NH}$ resulting in positive/negative anomalies of precipitation in the NH tropics ${ }^{8-14}$. A slight perturbation in this largescale tropical atmospheric circulation by the internal or external climate forcings will have substantial consequences for the hydrologic cycle ${ }^{15-20}$. The response of large-scale Hadley circulation to anthropogenic greenhouse gas forcing and the resultant variation in the hydrologic cycle have been studied ${ }^{21-23}$. Focusing on the later part of the 20th century, a large number of studies have shown a widening, strengthening and poleward shift of $\mathrm{HC}$ and associated changes in the tropical belt ${ }^{24}$. It has been hypothesized that a weaker rate of precipitation growth $\left(\sim 2 \% \mathrm{~K}^{-1}\right)$ under global warming with a growth rate of $7 \% \mathrm{~K}^{-1}$ for the atmospheric water vapour would result from the weakening of this large-scale overturning circulation in the atmosphere. A comprehensive mechanism of strengthening and expansion of $\mathrm{HC}$ is still far from completion. However, previous observational and model-based studies have linked these changes in HC to global warming ${ }^{24-26}$, stratospheric ozone depletion ${ }^{6,24-25}$ and associated tropospheric warming and stratospheric cooling ${ }^{14}$. The sensitivity of HC to climate forcings such as global warming and circulation changes such as El Niño Southern Oscillations (ENSO) has been well discussed. However, fewer studies are available regarding the impact of volcanic radiative forcing on $\mathrm{HC}$, especially on the Intertropical Convergence Zone (ITCZ) and subsequent changes in the water budget over the tropical regions ${ }^{15,16,27-29}$. Some studies have discussed the widening and poleward expansion of the midlatitude jets and $\mathrm{HC}$ in the past couple of decades ${ }^{8-10,12-14,30,31}$. Polvani and Kushner $^{32}$ suggest that ozone depletion could be responsible for the recent widening of $\mathrm{HC}^{33}$, as it may induce an equator-to-pole temperature gradient in the stratosphere that consequently affects $\mathrm{HC}$. However, Polvani et al. ${ }^{33}$ focused on the response of $\mathrm{HC}$ in the Southern Hemisphere 
(i.e. JJA season in the Southern Hemisphere). Recently, it has been established that this expansion of HC is partly attributed to ozone-induced stratosphere cooling, tropospheric heating (caused by global warming) and resultant stratosphere-troposphere temperature gradient ${ }^{14}$, and associated pressure and wind changes.

It has also been shown in previous studies that stratospheric aerosols cause warming in the lower stratosphere as well as cooling in the troposphere and at the surface. Such post-eruption changes consequently initiate equatorto-pole thermal gradient in the lower stratosphere as well as the hemispheric land-sea thermal gradient at the surface. Therefore, these changes are anticipated to cause a significant effect on Hadley circulation ${ }^{16}$, presumably in an opposite direction, as is the case under global warming scenarios $^{24}$. Hence, understanding the sensitivity of HC circulation following volcanic eruptions, such as its movement, strengthening or weakening is essential for human activities. Moreover, this circulation is directly related to the precipitation activity in the tropics, and with other large-scale circulations that affect human activities through changes in surface winds, precipitation, droughts, etc. Thus, it is important to study the possible changes in the tropical Hadley circulation and tropical convective activities, under a climate change environment, and their consequences following explosive tropical eruptions.

To better understand such effects, we studied the response of HC following El Chichón and Pinatubo tropical eruptions. We chose these two as they erupted in a satellite era and have better observational records, resulting in a better chance to compare and validate model results with observations.

We used a state-of-the-art global atmospheric model with very high spatial resolution, typically comparable to that of regional climate models, to study the sensitivity of $\mathrm{HC}$ to radiative perturbations caused by large-scale tropical volcanic eruptions. We focused on the following questions. (1) How is HC modulated following tropical volcanic eruptions? (2) How sensitive is ITCZ, especially the African and South Asian ITCZ to volcanic perturbations? (3) How well can HIRAM (effectively at $50 \mathrm{~km}$ and $25 \mathrm{~km}$ horizontal grid resolutions) simulate posteruption $\mathrm{HC}$ circulation and ITCZ shift?

\section{Model, data and methodology}

In this study, a high-resolution atmospheric model (HIRAM), developed at the Geophysical Fluid Dynamics Laboratory (GFDL) is used to assess the sensitivity of Hadley circulation and ITCZ to El Chichón and Pinatubo explosive tropical volcanic eruptions. HIRAM is based on the GFDL-atmospheric model version 2; AM2 (ref. 34) with increased horizontal and vertical resolution (model top reaches $10 \mathrm{hPa}$ with 32 vertical layers instead of 24), to better resolve tropospheric-stratospheric interactions, as well as simplified parameterization for moist convection and large-scale stratiform cloudiness. The model top at $10 \mathrm{hPa}$ reaches the middle stratosphere, which is sufficient to cover post-eruption climatic processes taking place in the lower stratosphere and upper troposphere, that are especially important for volcanicinduced climatic interactions. It uses cubed-sphere finitevolume dynamical core ${ }^{35}$. A detailed description of HIRAM can be found at: http:www.gfdl.noaa.gov/hiram. We employed Atmospheric Model Intercomparison Project (AMIP) style simulations of HIRAM effectively at 50 and $25 \mathrm{~km}$ horizontal resolutions ${ }^{20,36}$. This high resolution is comparable to that of regional climate models and is important to better resolve regional-scale dynamic features that are important, especially in the tropics. In these HIRAM-AMIP simulations, the model is forced using Hadley Center observed sea surface temperature (SST) and sea-ice boundary conditions ${ }^{37}$. Three different realizations covering the period 1976-2008 were produced using different SST initial conditions that were obtained after several integrations of the atmosphere-only model. The first three years of the simulation period were excluded from the analysis in order to avoid spin-up effects. The aerosol data for both the eruptions used in this model were calculated following Stenchikov et al. ${ }^{38}$. To have a reliable comparison with observations, we selected wellobserved tropical volcanic eruptions, i.e. El Chichón of March 1982 and Mount Pinatubo of June 1991.

We have compared HIRAM simulation results with 20th Century Reanalysis (20CR) of National Oceanic and Atmospheric Administration (NOAA) and ERA-Interim reanalysis of European Centre for Medium-Range Weather Forecasts (ECMWF). University of Delaware (UDEL) precipitation data (available over land only) has also been used to compare post-eruption model precipitation response $\mathrm{s}^{39}$. A two-tailed Student's $t$-test is employed to account for post-eruption significant responses at $95 \%$ confidence level. 20CR is a comprehensive global atmospheric dataset spanning the 20 th century at six-hourly temporal and $2^{\circ}$ spatial resolution. It is produced using observed interpolated monthly SST and sea-ice distribution from the Hadley Centre SST and sea-ice dataset ${ }^{36}$ as prescribed boundary conditions. It uses an ensemble Kalman filtering data assimilation method and a new version of the National Centers for Environmental Prediction (NCEP) Global Forecast System atmosphere-land global numerical weather prediction model to generate background 'first guess' fields ${ }^{40}$. The annual averages of the time-varying $\mathrm{CO}_{2}$ concentration, volcanic aerosols and downward solar radiation flux used in 20CR have been specified as described in Saha et al. ${ }^{41}$. The ERA-Interim dataset used in this study is a reanalysis that is based on an assimilation system that includes a four-dimensional variational analysis (4D-Var) with a $12 \mathrm{~h}$ analysis window. The spatial resolution of the ERA-Interim dataset is 

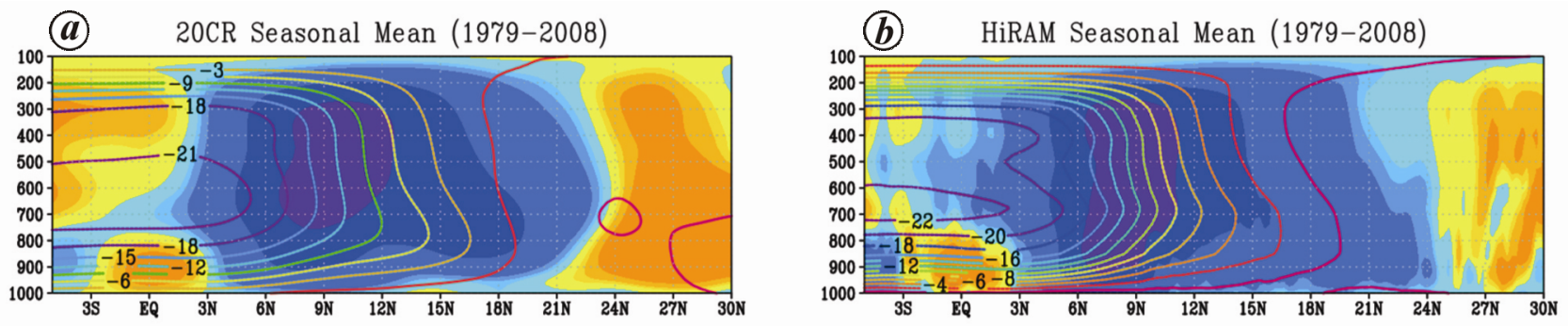

(c) 20CR El Chichon Two Seasons Anom
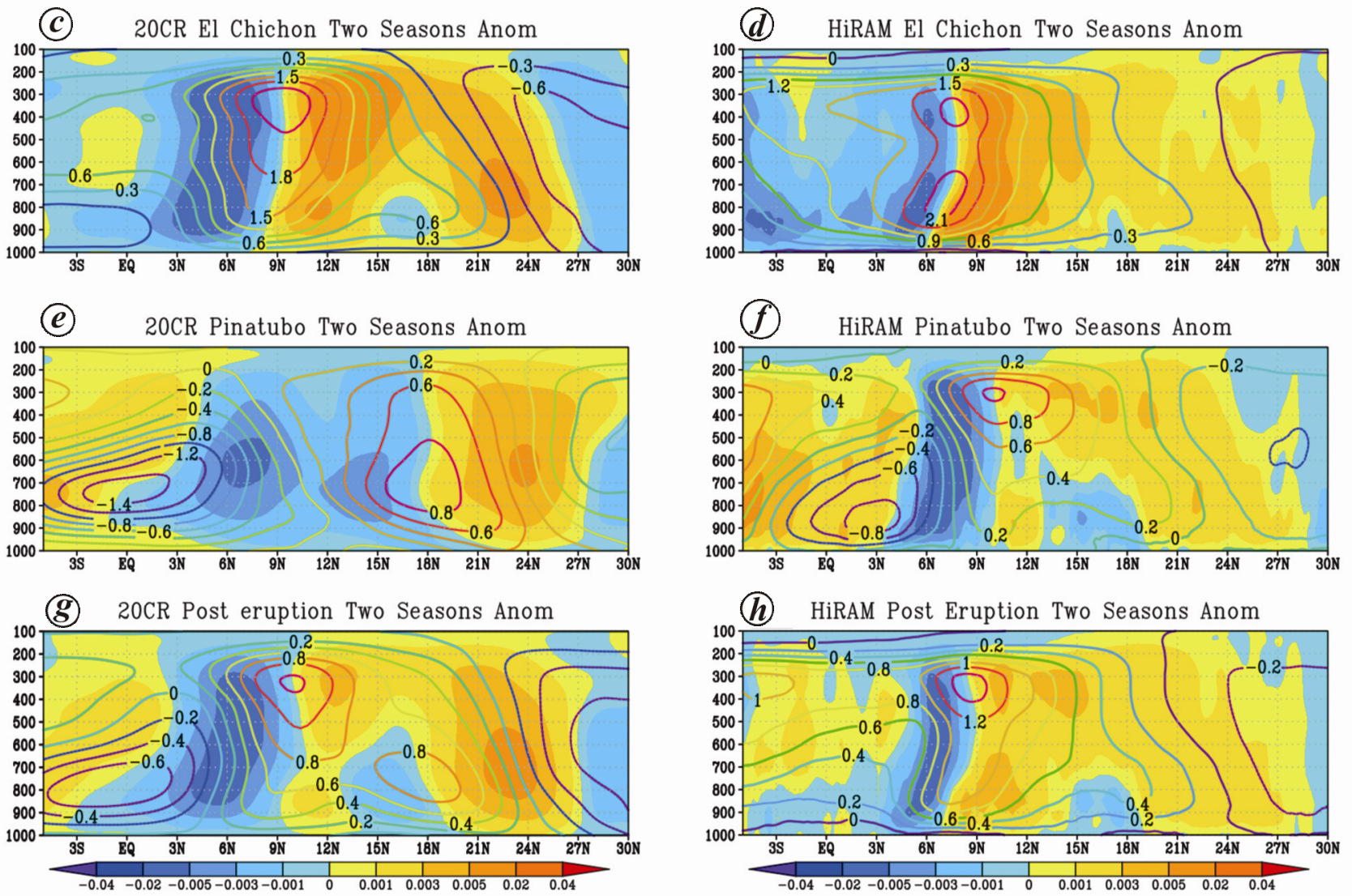

Figure 1. $\boldsymbol{a}, \boldsymbol{b}$, Zonal mean omega (vertical velocity in shaded colours; $\mathrm{Pa} / \mathrm{s}$ ) and zonal mean meridional mass stream function (in contours; $10^{8} \mathrm{~kg} / \mathrm{s}$ ) mean patterns calculated for the period 1979-2008; and post-eruption two summer seasons averaged anomaly patterns following (c, $\boldsymbol{d}$ ) El Chichón $(\boldsymbol{e}, \boldsymbol{f})$ and Pinatubo. $\boldsymbol{g}, \boldsymbol{h}$, Two summer seasons averaged anomaly composited following both the El Chichón and Pinatubo eruptions from 20th century NOAA reanalysis (left panel) and HIRAM model at $25 \mathrm{~km}$ (right panel). The positive (negative) shaded values in colour bar represent sinking (rising) branch of Hadley cell (HC).

approximately $80 \mathrm{~km}$ on 60 vertical levels from the surface up to $0.1 \mathrm{hPa}$ (ref. 42).

To simulate the impact of volcanic eruptions, we have shown anomalous response of different climatological parameters by considering their departure from long-term summer (JJA) seasonal mean that is computed for the period 1979-2008. This seasonal mean summer climatology is computed after excluding two post-eruption summer seasons following both the eruptions. To reduce noise, model results are presented (both for 50 and $25 \mathrm{~km}$ simulations) by averaging over three ensemble members. As large volcanic eruptions induce atmospheric impacts for 2-3 years, anomalous responses are calculated by averaging over two summer seasons following both the El
Chichón and Pinatubo eruptions, which are called posteruption anomalous responses.

\section{Results and discussion}

\section{Vertical wind and meridional mass stream function changes}

To quantify the sensitivity of $\mathrm{HC}$ to volcanic radiative forcing, in Figure 1, the zonal mean omega (vertical wind $(\mathrm{Pa} / \mathrm{s})$, displayed in shaded colours) and zonal mean meridional mass stream function $\left(10^{8} \mathrm{~kg} / \mathrm{s}\right.$, displayed in contours) are shown. The negative and positive values of 


\section{RESEARCH ARTICLES}
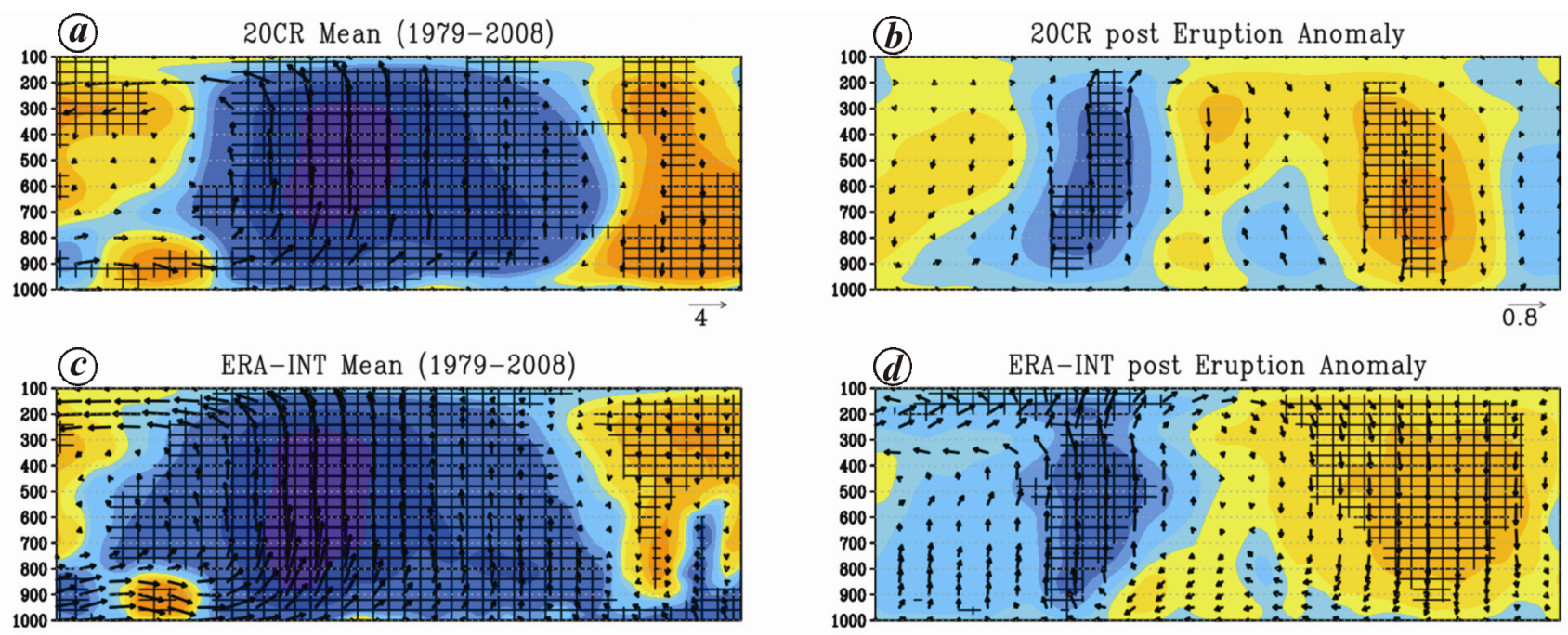

$\overrightarrow{4}$

$\overrightarrow{0.8}$
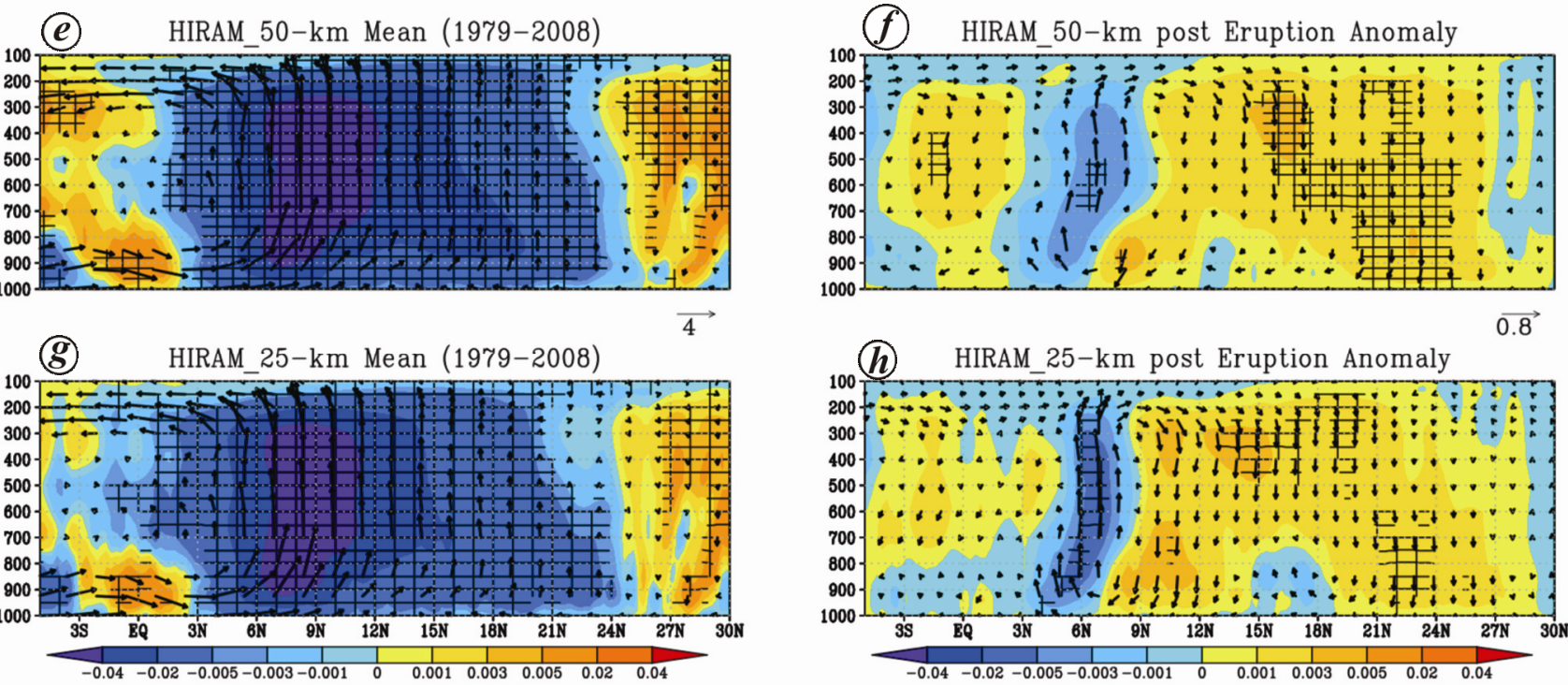

Figure 2. Mean (left panel) and anomaly (right panel) of zonal mean omega (vertical velocity in shaded colors; Pa/s) with overlaid zonal mean wind vectors $(v ;-100 \times$ omega, $\mathrm{m} / \mathrm{s} ; 100 \times \mathrm{Pa} / \mathrm{s})$ in the latitude-pressure plane. The mean pattern (calculated using the $1979-2008$ period) is shown using (a) 20CR, (c) ERA-Interim, (e) HIRAM at $50 \mathrm{~km}$ and (g) HIRAM at $25 \mathrm{~km}$ and the post-eruption (following both the El Chichón and Pinatubo) two summer seasons averaged anomaly patterns is shown using $(\boldsymbol{b})$ 20CR, (d) ERA-Interim, ( $\boldsymbol{f})$ HIRAM at $50 \mathrm{~km}$ and $(\boldsymbol{h})$ HIRAM at $25 \mathrm{~km}$. Positive shaded values in colour bar represent sinking motion, whereas negative values represent the rising branch of HC. Hatching shows areas where the mean and anomaly patterns are significant at $95 \%$ confidence level.

omega in these plots represent the ascending and descending branch of $\mathrm{HC}$ circulation respectively. The top panel (Figure $1 a$ and $b$ ) shows mean pattern and rest of the panels show anomalies (averaged over two seasons following each eruption) for the post-eruption El Chichón and Pinatubo cases. The mean pattern is computed using total simulation period (i.e. 1979-2008) after excluding two post-eruption summer seasons both for the 20CR and HIRAM simulation. Figure $1 c, d$ and $e, f$ shows HC anomalous response for the El Chichón and Pinatubo eruptions respectively. Figure $1 \mathrm{~g}$ and $h$ shows $\mathrm{HC}$ composite response following both the El Chichón and Pinatubo eruptions.

Both the reanalysis and model results depict a weakening of the $\mathrm{NH}$ summer $\mathrm{HC}$ and southward migration of its rising branch, the ITCZ, after both the eruptions. Both the El Chichón (Figure $1 c$ and $d$ ) and Mount Pinatubo (Figure $1 e$ and $f$ ) cause shortening, weakening and equatorward movement of the rising branch of northern HC. The anomalous patterns of vertical velocity and associated meridional mass stream function (especially for the El Chichón eruption) show more pronounced weakening and southward migration of the $\mathrm{HC}$ in the model than in the reanalysis. The rising and sinking limbs of the northern $\mathrm{HC}$ following El Chichón eruption intersects at $6^{\circ} \mathrm{N}$ in the model compared to $20 \mathrm{CR}$, where they meet at around $8^{\circ} \mathrm{N}$ (Figure $1 c$ and $d$ ) implying that model shows stronger southward shift. The response of zonal mean vertical velocity and associated meridional mass stream function both for the El Chichón and Pinatubo eruptions 

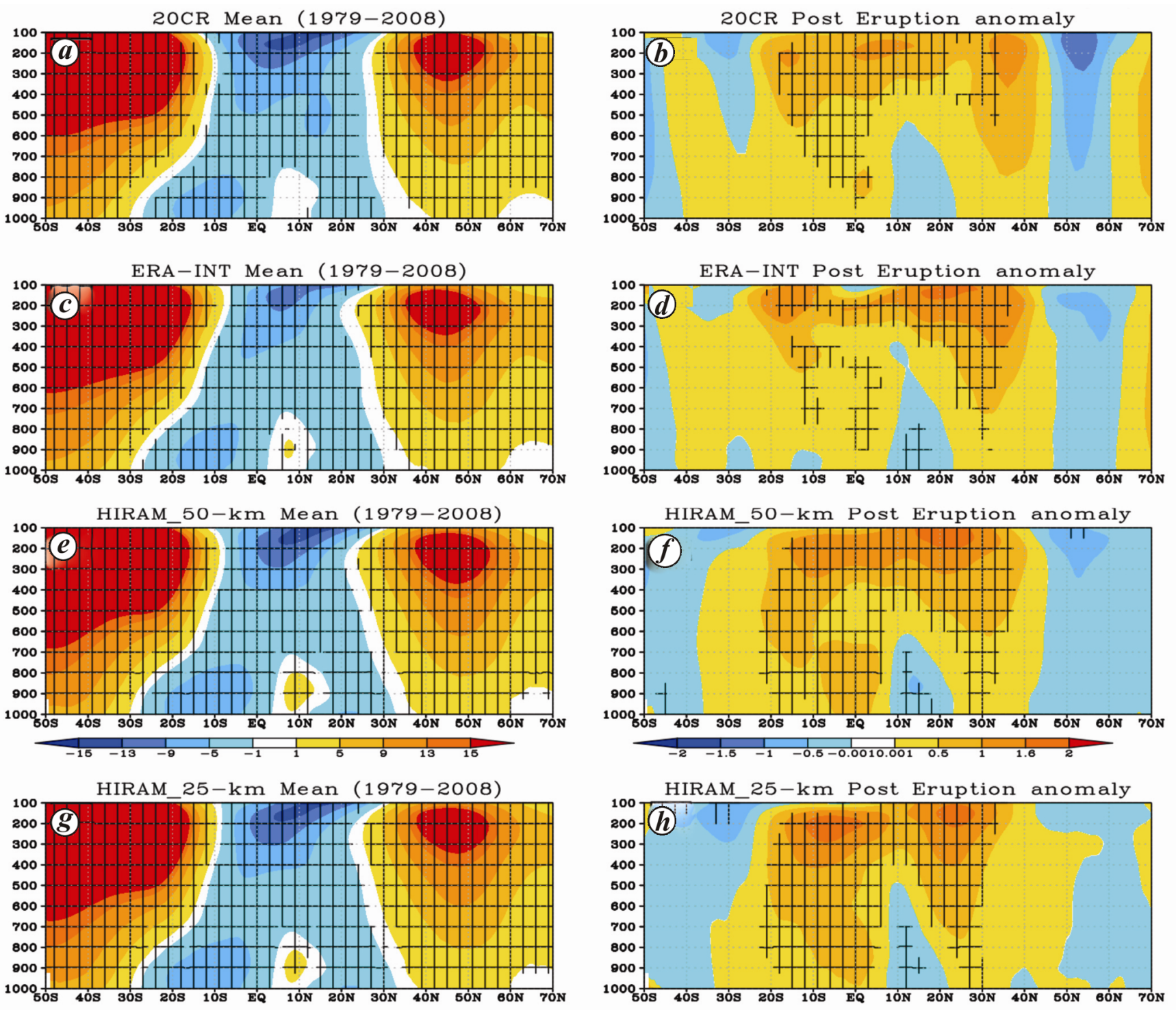

Figure 3. Global zonally averaged zonal wind (m/s) mean pattern using (a) 20CR, (c) ERA-Interim, (e) HIRAM at $50 \mathrm{~km}$ and (g) HIRAM at $25 \mathrm{~km}$ and anomaly response (averaged for two summer seasons following both the eruptions) using (b) 20CR, (d) ERA-Interim, $(\boldsymbol{f})$ HIRAM at $50 \mathrm{~km}$ and $(\boldsymbol{h})$ HIRAM at $25 \mathrm{~km}$. Mean response is calculated using the 1979-2008 period after excluding two summer seasons following both the eruptions and anomaly following each eruption is calculated using this mean. Hatching shows areas where the mean and anomaly patterns are significant at $95 \%$ confidence level.

is somehow more compact in model than 20CR (Figure $1 \mathrm{~g}$ and $h$ ). The southward shift is also more obvious in the model simulation compared to $20 \mathrm{CR}$, presumably because HIRAM has very high resolution and therefore resolves Hadley dynamic features reasonably better (especially at regional scales) than 20CR and also because model results are presented by averaging over three realizations which could minimize the effect of internal noise. We also noticed that the El Chichón eruption shows slightly stronger southward shift than the Pinatubo eruption (both in the model and 20CR) presumably because the former erupted slightly farther northward to the equator compared to the latter and therefore produces stronger hemispheric thermal gradient at the surface, re- sulting in stronger shift to updraft branch of HC. A slight spatial inconsistency between the model and 20CR, especially following the Pinatubo eruption, could be partly accounted for by the contribution of varying patterns caused by internal variability signal that could be different in the model and 20CR.

To further understand the statistical significance of $\mathrm{HC}$ response following both these tropical eruptions, we plotted vertical velocity pattern and associated wind vectors (Figure 2) using different reanalysis products. As both the El Chichón and Pinatubo eruptions roughly induce similar impact (i.e. weakening and southward shift of ITCZ), henceforth, we show composite (averaged over both the eruptions) patterns only. The weakening and southward 

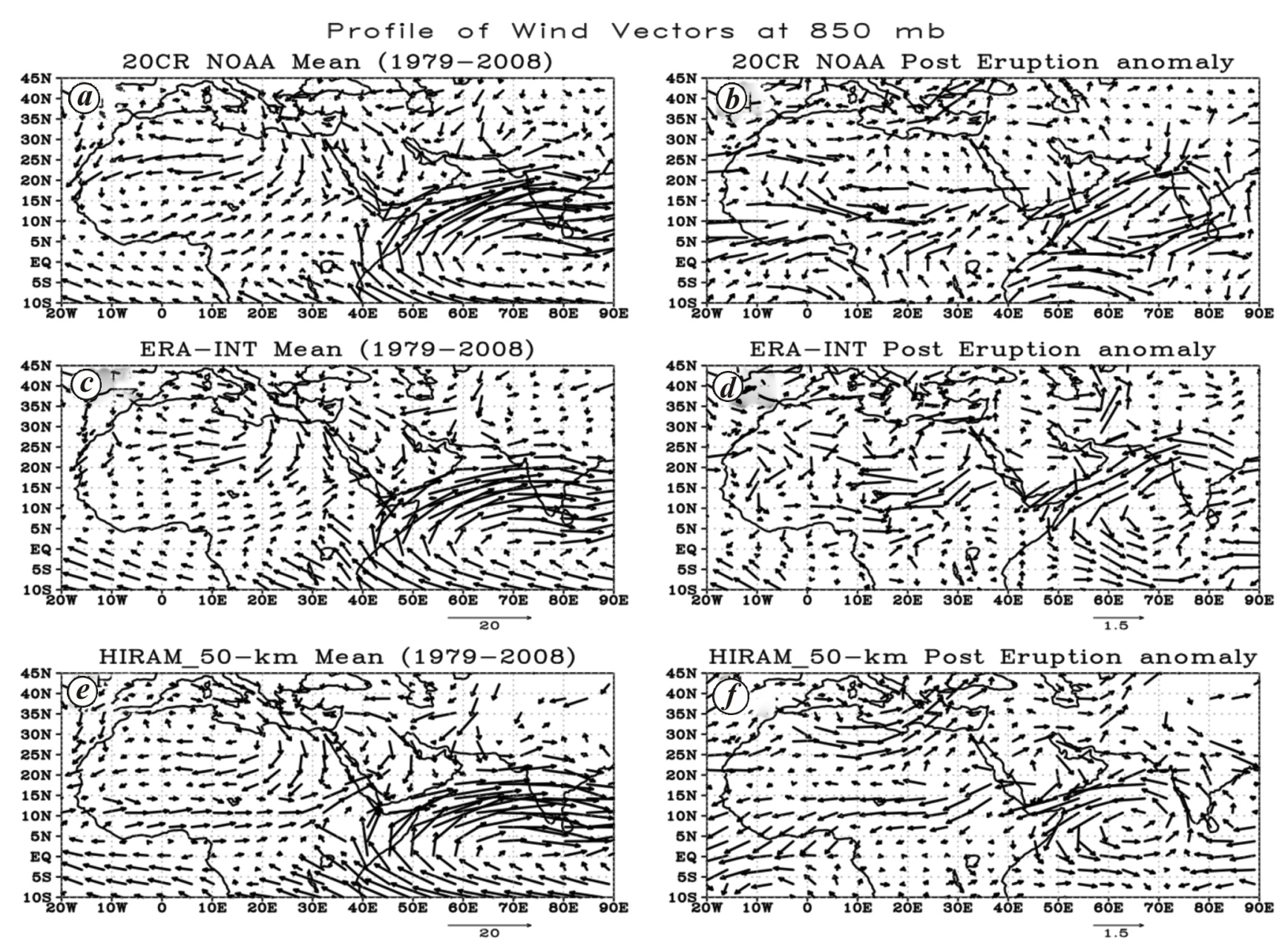

HIRAM 50-km Post Eruption anomaly
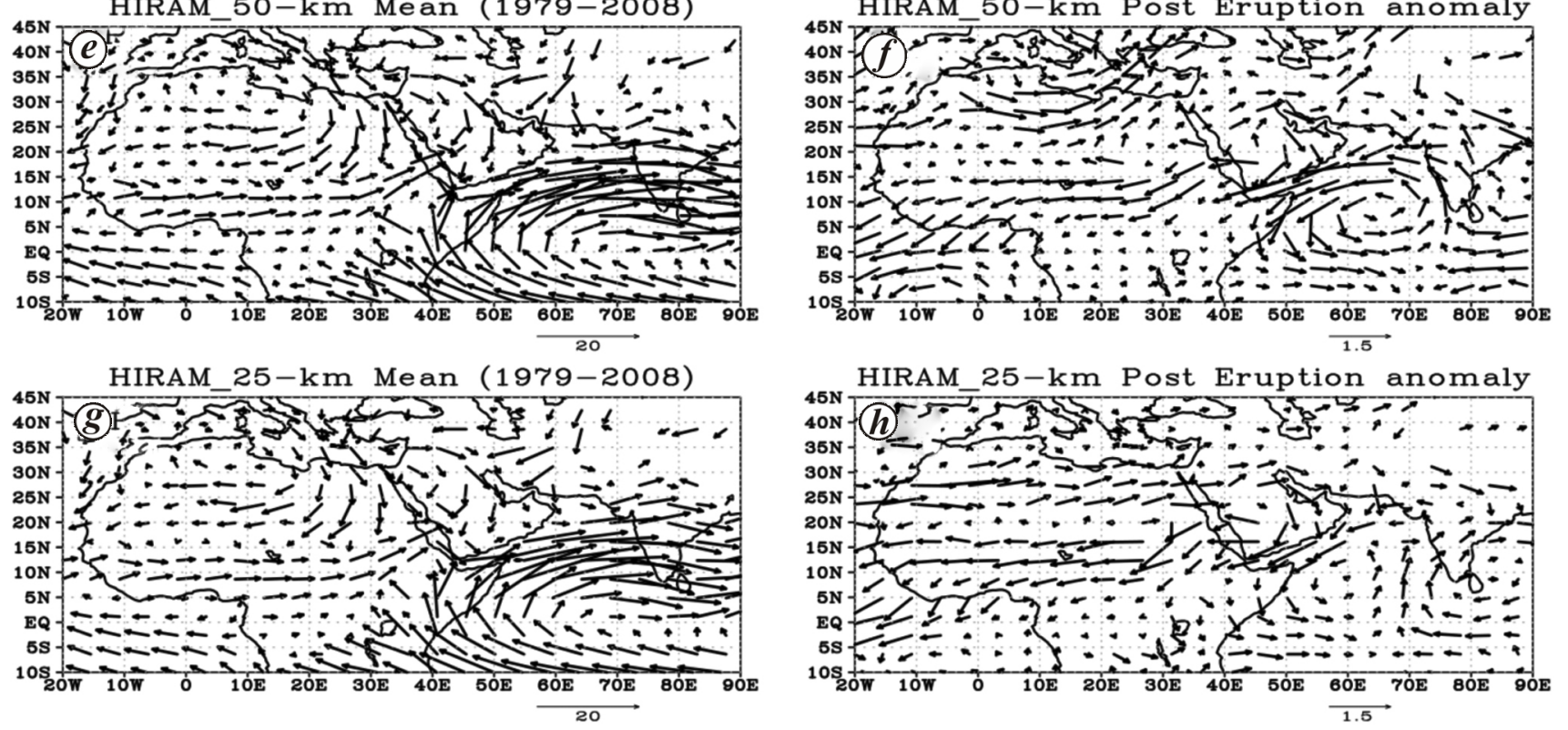

Figure 4. Summer (JJA) mean and post-eruption two summer seasons averaged wind vector $(\mathrm{m} / \mathrm{s}$ ) anomaly (composited for El Chichón and Pinatubo eruptions) from $(\boldsymbol{a}, \boldsymbol{b}) 20 \mathrm{CR},(\boldsymbol{c}, \boldsymbol{d})$ ERA-Interim and $(\boldsymbol{e}, \boldsymbol{f})$ HIRAM at $50 \mathrm{~km}$ and $(\boldsymbol{g}, \boldsymbol{h}) 25 \mathrm{~km}$ horizontal resolutions. The mean wind vector plots are computed over the period 1979-2008 after excluding two post-eruption summer seasons and anomaly is shown as a composite response averaged over two summers following both the eruptions.

shift is obvious, and rising and sinking anomalies of the vertical velocity are significant at $95 \%$ confidence level in the reanalysis (i.e. ERA-INT and 20CR). However, both the reanalysis show some spatial differences, such that rising branch is slightly wider in the reanalysis compared to model response. The model-produced mean and post-eruption anomaly responses (both in Figures 1 and 2) are in good agreement, both qualitatively and quantitatively, with the 20th century reanalysis product; however, post-eruption shrinking and shortening of the $\mathrm{HC}$ rising branch is more pronounced in HIRAM simulations than in 20CR and ERA-Interim reanalysis. This could be due to the former having a much finer resolution compared to the latter products. Moreover, it shares averaged response produced using three ensemble members, which presumably minimizes the contribution introduced by internal variability. The model at $50 \mathrm{~km}$ resolution shows a comparable response to the reanalysis products; however, the rising branch of $\mathrm{HC}$ is more compact in the $25 \mathrm{~km}$ model resolution compared to the reanalysis and $50 \mathrm{~km}$ model simulation, suggesting that HIRAM with fine resolution resolves HC feature better compared to its low-resolution 


\section{RESEARCH ARTICLES}
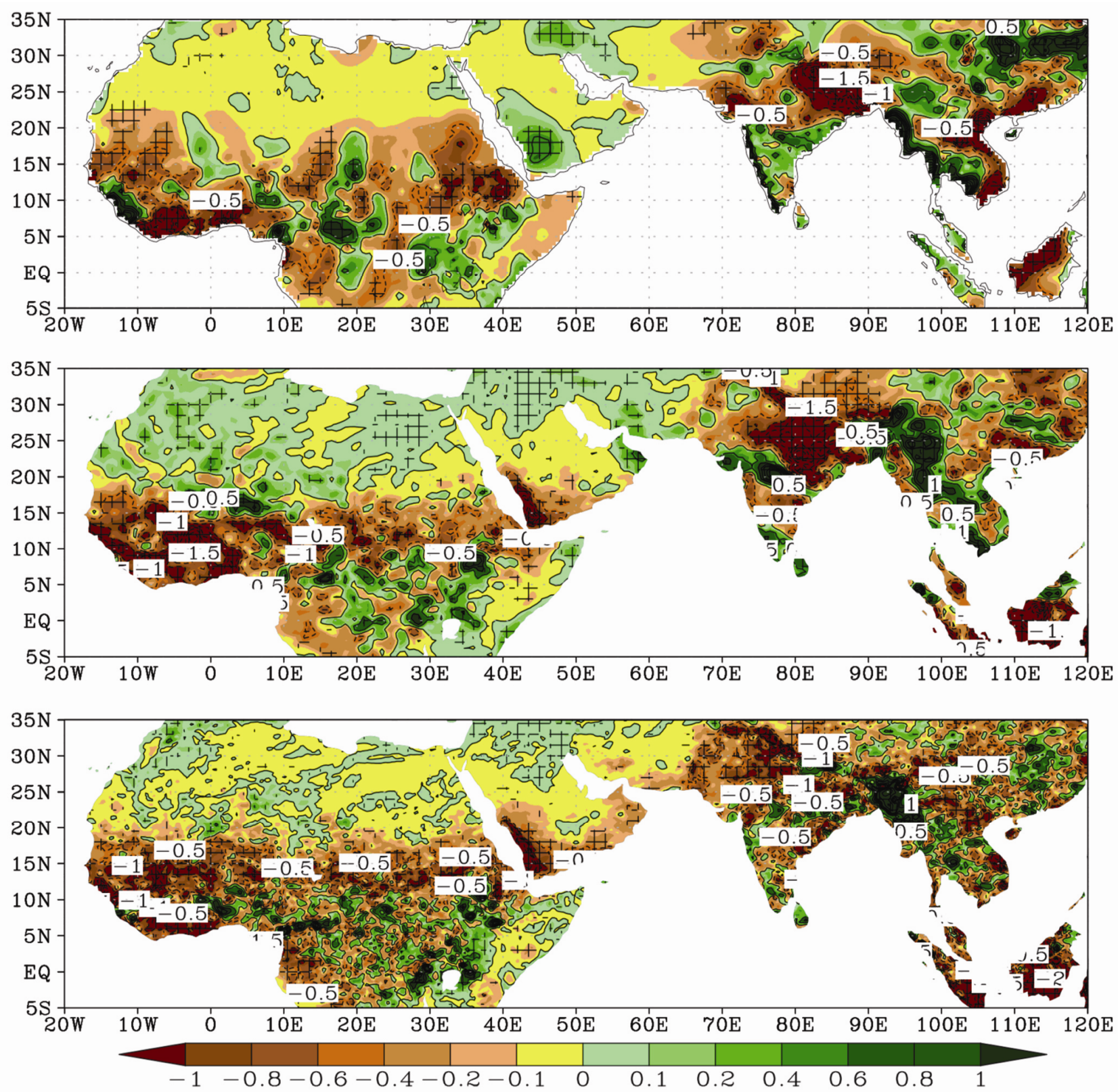

Figure 5. Post-eruption two summer (JJA) seasons averaged precipitation anomaly (mm/d) composites following El Chichón and Pinatubo eruptions using UDEL (top panel), HIRAM at $50 \mathrm{~km}$ (middle panel) and HIRAM at $25 \mathrm{~km}$ (bottom panel). Hatching shows areas where the precipitation anomaly pattern is significant at $95 \%$ confidence level.

counterpart and low resolution reanalysis products. The location and intensity of the rising and sinking branch can also be seen from the overlay contour plots of meridional mass stream function following each eruption (Figure 1), and these are consistent with vertical wind patterns. The intensities of the wind vectors (Figure 2) are comparable between HIRAM and the reanalysis products.

\section{Midlatitude jet stream response}

To further understand the physical mechanism governing post-eruption HC changes, we examined the zonally averaged zonal velocity $(\mathrm{m} / \mathrm{s})$ following both eruptions (Figure 3 ). Both the reanalysis and model results show an equatorward movement of midlatitude jet streams. The subtropical jet streams form near the boundary of the Hadley and Ferrel cells, hence, an equatorward displacement of these jets after both these eruptions imply that the Hadley cell is displaced equatorward. HIRAM (especially at $25 \mathrm{~km}$ ) shows more pronounced features of equatorward displacement of subtropical jets in both the hemispheres, suggesting that volcanic-induced stratospheric and tropospheric thermal gradient could induce changes in zonal wind pattern that might affect 


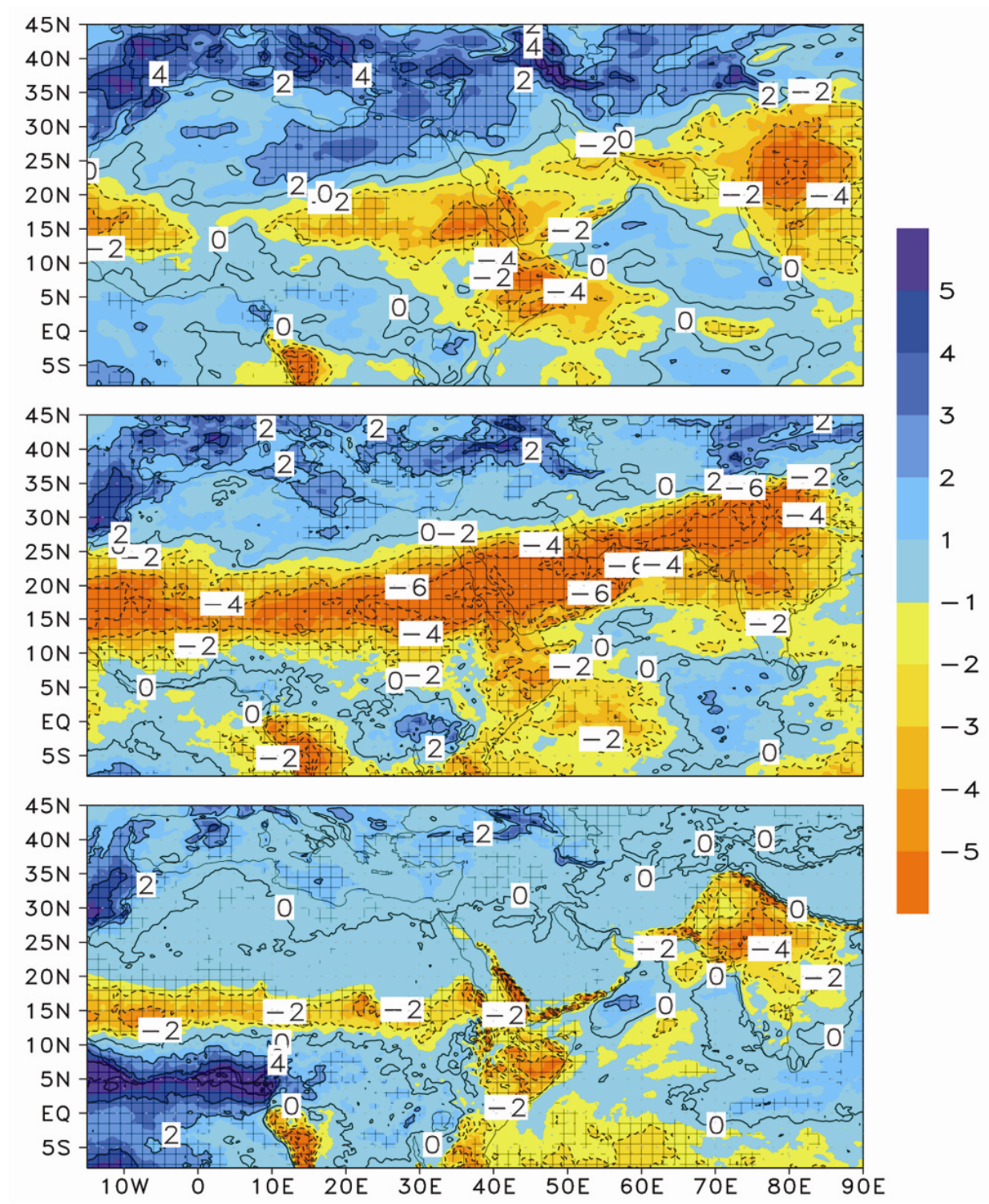

Figure 6. Post-eruption two summer seasons averaged total cloud content anomaly (\%) composite following El Chichón and Pinatubo eruptions using HIRAM at $50 \mathrm{~km}$ (top panel), at $25 \mathrm{~km}$ (middle panel) and low cloud content anomaly using HIRAM at $25 \mathrm{~km}$ (bottom panel). Hatching shows areas where the cloud content anomaly pattern is significant at $95 \%$ confidence level.

$\mathrm{HC}$ in an opposite direction, as is caused under the global warming scenario ${ }^{16,24,26,27,29}$. Both the mean and anomalous patterns (Figure 3 ) of the jet streams are well simulated by the HIRAM model.

\section{Wind, precipitation and cloud response}

Let us consider how the tropical eruptions affect African and South Asian monsoonal circulation. Figure 4 displays wind vector seasonal mean (left panel) and anomalous responses at $850 \mathrm{hPa}$ for post-eruption periods (right panel) over the African and South Asian regions employing 20CR, ERA-Interim and HIRAM (at 50 and $25 \mathrm{~km}$ hori- zontal resolution). Both the African and Indian monsoon wind patterns show post-eruption (averaged over two seasons following both the El Chichón and the Pinatubo eruptions) weakening in the respective monsoons ${ }^{27,30}$. The HIRAM model reproduces cross-equatorial monsoonal current and reversal of wind $(\mathrm{m} / \mathrm{s})$ reasonably well both in the mean plot and anomaly patterns. The model simulation (at both resolutions) captures well the mean and post-eruption anomaly patterns of cross-equatorial low-level Somali jets. Model-generated wind anomalous responses show more pronounced weakening patterns both for Indian and African monsoon regions compared to 20CR and ERA-Interim, which show a slightly different pattern over the western part of the central African 


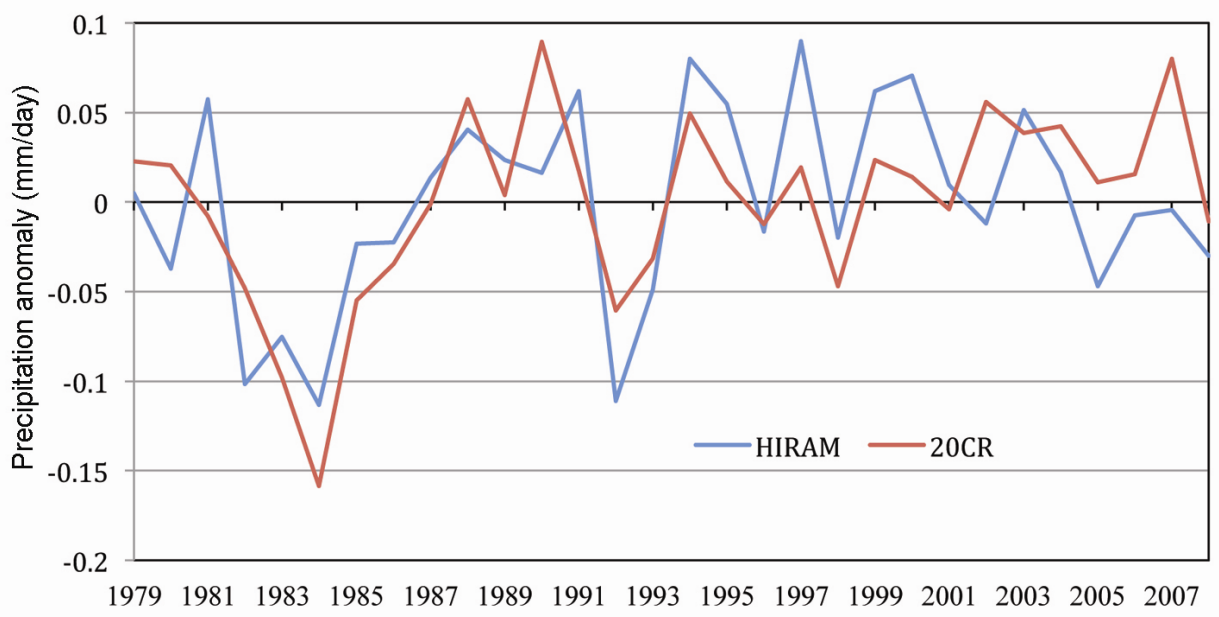

Figure 7. Summer (JJA) precipitation anomaly $(\mathrm{mm} / \mathrm{d})$ averaged over $0^{\circ}-360^{\circ} \mathrm{E}, 3^{\circ} \mathrm{S}-35^{\circ} \mathrm{N}$.

domain, that could be accounted for by coarse resolution of the reanalysis models together with scarcity of observational measurements over the African domain. We also looked at post-eruption (averaged over both the El Chichón and Pinatubo eruptions) spatial pattern of precipitation anomaly over the northern $\mathrm{HC}$ region during summer (JJA) season (Figure 5). A decreased precipitation anomaly both from the observation and the model is evident over the entire $\mathrm{HC}$ with a slight increasing pattern over southern parts of India, Central Africa (south of tropical Sahel rain-belt region) and Bangladesh that could be attributed to the southward shift of the rising branch of $\mathrm{HC}^{28-30}$. The decrease in precipitation is a result of posteruption weakening of the rising branch of HC (Figures 1 and 2), and associated decreased cloud content (Figure 6). Similar decreased cloud amount and associated precipitation changes over the tropical regions following high latitude as well as tropical eruptions were also reported in earlier studies ${ }^{29,30}$. The pattern of precipitation anomaly and cloud content, especially low clouds (Figures 5 and Figure 6 respectively) suggest a weakening and southward shift of the ITCZ as a result of post-eruption weakened thermal gradient between ocean and inland continents $^{30,31}$. HIRAM-produced precipitation anomaly patterns following both the eruptions are in good agreement with the UDEL observations (Figure 5). The precipitation deficit over the tropical areas reaches a maximum value of $-1.5 \mathrm{~mm} /$ day both in HIRAM simulations and UDEL observation. These post-eruption precipitation responses suggest that the strong tropical volcanic eruptions result in weakening of the tropical Hadley circulation, which may produce droughts-like conditions in the African and South Asian tropical regions. These results are consistent with earlier studies $^{15,16}$. Figure 7 shows global zonally averaged summer season precipitation anomaly $(\mathrm{mm} / \mathrm{d})$ averaged over a selected region $\left(3^{\circ} \mathrm{S}-35^{\circ} \mathrm{N}\right)$ that covers mainly the $\mathrm{HC}$ regions. It is produced using $20 \mathrm{CR}$ and HIRAM simula- tion (at $25 \mathrm{~km}$ ) after removing ENSO-related variations. Previous studies have suggested eliminating possible ENSO signals ${ }^{15,43}$, as both the eruptions occurred during an ENSO event, which could modulate volcanic signal. The ENSO-related contribution is filtered out using simple linear regression technique with the Niño 3.4 SST index for summer (JJA) season ${ }^{15,43,44}$. The decreased precipitation anomaly is evident following both the eruptions, which shows a weakening of moisture inflow towards inland regions caused by weakening of posteruption hemispheric thermal gradient between land and ocean $^{28}$. This decreased precipitation after both the eruptions is consistent with earlier studies ${ }^{28,29}$. Both HIRAM and $20 \mathrm{CR}$ product are in good agreement. Figure 7 shows that the northern branch of $\mathrm{HC}$ circulation is weakened as a result of weakened land-sea thermal contrast following both the eruptions, which results in decreased amount of water-laden air driven from the ocean surface towards inland regions ${ }^{30}$. Hence, a decreased inflow of moisture content towards inland tropical regions results in decreased precipitation over the tropical convective regions in summer.

\section{Summary and conclusion}

The sensitivity of $\mathrm{HC}$ circulation to the warming induced by anthropogenic greenhouse forcing has been well discussed in previous studies. However, response of HC to volcanic aerosol radiative forcing has received less attention. In this study, we have analysed the post-eruption response of Hadley circulation in boreal summer (JJA) season. For this, we conducted simulations of the late 20th century explosive eruptions, i.e. El-Chichón and Pinatubo, applying GFDL-HIRAM model effectively at 50 and $25 \mathrm{~km}$ horizontal grid spacing. This high-resolution global modelling system is essential to better resolve post-eruption regional dynamic circulations (such as 
Asian and African summer monsoons), and their interaction and modulation by global-scale circulations (such as tropical Hadley and Walker circulations) which are important, especially in the tropics. This study shows that the massive NH tropical eruptions significantly affect midlatitude jet streams in the boreal summer season which in turn play a significant role in contracting and displacing the updraft branch of the northern HC towards the equator. The observational and model-produced results further indicate that the tropical eruptions cause significant surface cooling that results interhemispheric thermal asymmetry as well as weakened land and ocean thermal gradient. This weakened thermal gradient leads to decreased cloud content and moisture inflow towards inland tropical convective regions in summer resulting in a decreased precipitation, suggesting post-eruption drought-like conditions. HIRAM model effectively simulates a weakening of the NH summer $\mathrm{HC}$ and a southward displacement of its rising branch (i.e. ITCZ) in the posteruption summer season. However, HIRAM at $25 \mathrm{~km}$ horizontal resolution shows more pronounced displacement of midlatitude jet streams and associated HC response compared to 20CR, ERA-Interim and HIRAM at $50 \mathrm{~km}$ resolution. Our results clearly reveal that the posteruption changes in northern HC circulation and ITCZ cause weakening in the South Asian and African summer monsoon circulation systems. The model results are largely consistent with the observations and reanalysis products that emphasize that GFDL-HIRAM can be effectively used to simulate post-eruption dynamic circulation changes. This study indicates that volcanic eruptions significantly impact $\mathrm{HC}$ circulation. However, in-depth understanding of the impacts of volcanic eruptions on $\mathrm{HC}$ using high-resolution coupled modelling approach is needed to better account for post-eruption oceanic feedback and concomitant changes in $\mathrm{HC}$.

1. Lindzen, R. S. and Pan, W., A note on orbital control of equatorpole heat fluxes. Climate Dyn., 1994, 10, 49-57.

2. Oort, A. and Yienger, J., Observed interannual variability in the Hadley circulation and its connection to ENSO. J. Climate, 1996, 9, 2751-2767.

3. Cook, K. H., Hadley circulation dynamics: seasonality and the role of continents. In The Hadley Circulation: Present, Past and Future (eds Diaz, H. F. and Bradley, R. S.), Springer, New York, USA, 2004, pp. 1-5.

4. Webster, P. J., The elementary Hadley circulation. In The Hadley Circulation: Present, Past and Future (eds Diaz, H. F. and Bradley, R. S.), Springer, New York, USA, 2004, p. 9-60.

5. Quan, X.-W. et al., Change of the tropical Hadley cell since 1950 In The Hadley Circulation: Past, Present, and Future (eds Diaz, H. F. and Bradley, R. S.), Cambridge University Press, New York, USA, 2004, pp. 85-120.

6. Seidel, D. J. and Randel, W. J., Recent widening of the tropical belt: evidence from tropopause observations. J. Geophys. Res., 2007, 112, D20113.

7. Gastineau, G., Le Treut, H. and Li, L., The Hadley and Walker circulation changes in global warming conditions described by idealized atmospheric simulations. J. Climate, 2009, 22, 39934013 .
8. Hudson, R. D., Andrade, M. F., Follette, M. B. and Frolov, A. D., The total ozone field separated into meteorological regimes - Part II: northern hemisphere mid-latitude total ozone trends. Atmos. Chem. Phys., 2006, 6, 5183-5191.

9. Davis, S. M. and Rosenlof, K. H., A multidiagnostic intercomparison of tropical-width time series using reanalyses and satellite observations. J. Climate, 2012, 25, 1061-1078.

10. Fu, Q. and Lin, P., Poleward shift of subtropical jets inferred from satellite-observed lower-stratospheric temperatures. J. Climate, 2011, 24, 5597-5603.

11. Nguyen, H., Evans, A., Lucas, C., Smith, I. and Timbal, B., The Hadley circulation in reanalyses: climatology, variability, and change. J. Climate, 2013, 26(10), 3357-3376.

12. Wilcox, L. J., Hoskins, B. J. and Shine, K. P., A global blended tropopause based on ERA data. Part II: trends and tropical broadening. Q. J. R. Meteorol. Soc., 2012, 138, 576-584.

13. Zhou, Y., Xu, K.-M., Sud, Y. and Betts, A., Recent trends of the tropical hydrological cycle inferred from Global Precipitation Climatology Project and International Satellite Cloud Climatology Project data. J. Geophys. Res., 2011, 116, D09101.

14. Fu, Q., Johanson, C. M., Wallace, J. M. and Reichler, T., Enhanced mid-latitude tropospheric warming in satellite measurements. Science, 2006, 312, 1179.

15. Trenberth, K. E. and Dai, A., Effects of Mount Pinatubo volcanic eruption on the hydrological cycle as an analog of geoengineering, Geophys. Res. Lett., 2007, 34, L15702.

16. Trenberth, K. E. Changes in precipitation with climate change. Climate Res., 2011, 47(1-2), 123-138.

17. Bala, G., Duffy, P. and Taylor, K., Impact of geoengineering schemes on the global hydrological cycle. Proc. Natl. Acad. Sci. USA, 2008, 105(22), 7664-7669.

18. Wild, M., Grieser, J. and Schär, C., Combined surface solar brightening and increasing greenhouse effect support recent intensification of the global land-based hydrological cycle. Geophys. Res. Lett., 2008, 35(17), L17706.

19. Dogar, M. M., Kucharski, F. and Azharuddin, S., Study of the global and regional climatic impacts of ENSO magnitude using SPEEDY AGCM. J. Earth Syst. Sci., 2017, 126, 30.

20. Dogar, M. M., Stenchikov, G., Osipov, S., Wyman, B. and Zhao, M., Sensitivity of the regional climate in the Middle East and North Africa to volcanic perturbations. J. Geophys. Res.: Atmos., 2017, 122(15), 7922-7948.

21. Held, I. and Soden, B., Robust response of the hydrological cycle to global warming. J. Climate, 2006, 19, 5686-5699.

22. Vecchi, G. A. and Soden, B. J., Global warming and the weakening of the tropical circulation. J. Climate, 2007, 20, 4316-4340.

23. Tao, L., Hu, Y. and Liu, J., Anthropogenic forcing on the Hadley circulation in CMIP5 simulations. Climate Dyn., 2016, 46(9-10), 3337-3350.

24. Seidel, D. J., Fu, Q., Randel, W. J. and Reichler, T. J., Widening of the tropical belt in a changing climate. Nature Geosci., 2008, 1(1), 21-24.

25. Johanson, C. M. and Fu, Q., Hadley cell widening: model simulations versus observations. J. Climate, 2009, 22(10), 2713-2725.

26. Kang, S. M. and Lu, J., Expansion of the Hadley cell under global warming: winter versus summer. J. Climate, 2012, 25(24), 83878393.

27. Iles, C. E. and Hegerl, G. C., The global precipitation response to volcanic eruptions in the CMIP5 models. Environ. Res. Lett., 2014, 9(10), 104012.

28. Haywood, J. M., Jones, A., Bellouin, N. and Stephenson, D., Asymmetric forcing from stratospheric aerosols impacts Sahelian rainfall. Nature Climate Change, 2013, 3(7), 660.

29. Joseph, R. and Zeng, N., Seasonally modulated tropical drought induced by volcanic aerosol. J. Climate, 2011, 24(8), 2045-2060.

30. Oman, L., Robock, A., Stenchikov, G. L. and Thordarson, T., High-latitude eruptions cast shadow over the African monsoon and 
the flow of the Nile. Geophys. Res. Lett., 2006, 33, doi: 10.1029/2006GL027665.

31. Barnes, E. A. and Polvani, L., Response of the midlatitude jets, and of their variability, to increased greenhouse gases in the CMIP5 models. J. Climate, 2013, 26(18), 7117-7135.

32. Polvani, L. M. and Kushner, P. J., Tropospheric response to stratospheric perturbations in a relatively simple general circulation model. Geophys. Res. Lett., 2002, 29(7), 1114.

33. Polvani, L. M., Waugh, D. W., Correa, G. J. and Son, S.-W., Stratospheric ozone depletion: the main driver of twentieth-century atmospheric circulation changes in the southern hemisphere. $J$. Climate, 2011, 24(3), 795-812.

34. Anderson, J. L., Balaji, V., Broccoli, A. J. and Cooke, W. F., The new GFDL global atmosphere and land model AM2-LM2: evaluation with prescribed SST simulations. J. Climate, 2004, 17(24), 4641.

35. Putman, W. M. and Lin, S.-J., Finite-volume transport on various cubed-sphere grids. J. Comput. Phys., 2007, 227, 55-78; doi:10.1016/j.jcp.2007.07.022.

36. Zhao, M., Held, I. M., Lin, S.-J. and Vecchi, G. A., Simulations of global hurricane climatology, interannual variability, and response to global warming using a $50-\mathrm{km}$ resolution GCM. J. Climate, 2009, 22(24), 6653-6678.

37. Rayner, N. A. et al., Global analyses of sea surface temperature, sea ice, and night marine air temperature since the late nineteenth century. J. Geophys. Res., 2003, 108(D14), 4407; 10.1029/ 2002JD002670.

38. Stenchikov, G., Hamilton, K., Stouffer, R. J., Robock, A., Ramaswamy, V., Santer, B. and Graf, H. F., Arctic oscillation response to volcanic eruptions in the IPCC AR4 climate models. J. Geophys. Res.: Atmos., (1984-2012), 2006, 111(D7).

39. Legates, D. R. and Willmott, C. J., Mean seasonal and spatial variability in gauge-corrected, global precipitation. Int. J. Climatol., 1990, 10(2), 111-127.

40. Compo, G. P. et al., The twentieth century reanalysis project. Q. J. R. Meteorol. Soc., 2011, 137(654), 1-28.

41. Saha, S. et al., The NCEP climate forecast system reanalysis. Bull. Am. Meteorol. Soc., 2010, 91(8), 1015-1057.

42. Dee, D. et al., The ERA-Interim reanalysis: configuration and performance of the data assimilation system. Q. J. R. Meteorol. Soc., 2011, 137(656), 553-597.

43. Robock, A. and Mao, J., The volcanic signal in surface temperature observations. J. Climate, 1995, 8(5), 1086-1103.

44. Gujarati, D. N., Basic Econometrics, Tata McGraw-Hill Education, New York, 2009, 5th edn.

ACKNOWLEDGEMENTS. I thank Earth Science and Engineering Department, King Abdullah University of Science and Technology, Thuwal, Saudi Arabia for providing computational facilities that were used to conduct model simulations. The observational and simulation results are available from the author upon request.

Received 4 June 2016; revised accepted 5 October 2017

doi: $10.18520 / \mathrm{cs} / \mathrm{v} 114 / \mathrm{i06} / 1284-1294$ 